\title{
Erythrocyte uridine diphosphate galactose-4- epimerase deficiency identified by newborn screening for galactosemia in the United States
}

\author{
Won G. Nga , Yan-Kang Xua , Tina M. Cowan ${ }^{\mathrm{b}}$, Miriam G. Blitzer ${ }^{\mathrm{b}}$, \\ Richard J. Allen ${ }^{c}$, Hans-Georg O. Bock ${ }^{\mathfrak{d}}$, Walter C. Kruckeberg ${ }^{\mathrm{d}}$ \\ and Harvey L. Levye \\ 'Division of Medical Genetics, Childrens Hospital Los Angeles and Department of Pediatrics, University \\ of Southern California School of Medicine, Los Angeles, CA, ${ }^{b}$ Division of Human Genetics, School of \\ Medicine, University of Maryland at Baltimore, Baltimore, $M D,^{\mathfrak{c}}$ Pediatric Neurology Section, \\ Deparıment of Pediatrics and Neurology, University of Michigan Medical Center, Ann Arbor, MI, \\ ${ }^{\mathrm{d} D i v i s i o n}$ of Medical Genetics, University of Mississippi Medical Center, Jackson, MS and ${ }^{\mathrm{e}}$ Newborn \\ Screening Program, State Laboratory Institute, Jamaica Plain, MA, USA
}

(Accepted 4 August 1993)

Eight infants (two whites and six blacks) with erythrocyte uridine diphosphate galactose-4epimerase (epimerase) deficiency were identified in four newborn screening programs for galactosemia in the United States. The initial biochemical findings in all cases were elevated blood galactose-1-phosphate with normal or only slightly increased blood galactose and normal galactose-1-phosphate uridyltransferase (GALT) activity. Epimerase deficiency was confirmed in erythrocytes by a two-step enzymatic assay involving fluorometric measurements of NADH generated by coupling the uridine diphosphate glucose dehydrogenase reaction to epimerase. Seven of the eight infants appeared to be clinically normal at birth and one newborn had neonatal jaundice. The infrequent recognition of epimerase deficiency is likely due to the methods of newborn screening for galactosemia which are often only for GALT deficiency and perhaps also due to incomplete follow-up of increased metabolite levels in newborn blood specimens with normal GALT activity. Our results confirm a preliminary report of a high frequency of erythrocyte epimerase deficiency in the American black population.

Key words: Galactosemia; Newborn screening; Uridine diphosphate galactose-4-epimerase deficiency; American black

\section{Introduction}

There are three inherited disorders of galactose metabolism in man resulting in elevation of blood galactose: galactokinase deficiency, galactose-1-phosphate

Correspondence to: Won G. Ng, Ph.D., Biochemical Genetics Laboratory, Division of Medical Genetics, Childrens Hospital Los Angeles, Box 11, 4650 Sunset Boulevard, Los Angeles, CA 90027, USA. 
uridyltransferase (GALT) deficiency, and uridine diphosphate galactose-4-epimerase (epimerase) deficiency [1]. The second of these disorders, GALT deficiency, is usually referred to as galactosemia.

Neonatal screening for galactosemia is performed worldwide. Presently 41 states and the District of Columbia in the US include this screening within their newborn screening programs; however, there is no uniform approach to this screening. Some laboratories use metabolite methods such as the Guthrie inhibition assay [2], the Paigen assay [3], the Fujimura method [4], or modification of the latter procedure [5-7], which detect accumulation of the metabolites galactose and galactose-1phosphate (Gal-1-P) by galactose dehydrogenase coupling. Others use an enzymatic assay for GALT activity, the most common of which is the blood spot assay of Beutler and Baluda [8]. Automated analysis of GALT activity from filter paper blood specimens has also been employed [9]. Some laboratories use a combination of metabolite and GALT activity determinations. In addition to identifying patients with GALT deficiency, the metabolite assays can also identify patients with galactokinase and epimerase deficiencies.

Galactosemia due to GALT deficiency is the most clinically severe and the most frequent of these disorders. It has an occurrence rate of about 1 in 62,000 , although this varies with different populations [10]. Galactokinase deficiency is associated with cataracts and seems to be very rare. Two types of epimerase deficiency based on clinical presentation have been described. One is considered benign with severe enzyme deficiency found in erythrocytes and leukocytes and near normal activity in liver and cultured skin fibroblasts [11,12]. Cultured lymphoblasts also showed substantial epimerase activity, suggesting an unstable mutant epimerase [13]. The other is associated with severe clinical manifestations similar to galactosemia with enzyme deficiency demonstrated in erythrocytes and cultured skin fibroblasts [14,15].

A number of cascs with the benign form of cpimerasc deficiency have been rcported in Switzerland [12] and Japan [16]. Herein we report the first cases of what appears to be the benign form of epimerase deficiency detected in four state screening programs in the United States. This study confirms the preliminary report of a high frequency of epimerase deficiency in the American black population [17].

\section{Material and Methods}

All reagents for the assay of UDPGal-4-epimerase were from Sigma Chemical Co. (St. Louis, MO, USA). These include uridine diphosphate galactose (UDPGal), uridine diphosphate glucose (UDPGlc), nicotinamide adenine dinucleotide oxidized, nicotinamide, glycine, and UDPGlc dehydrogenase (Sigma U5500).

Blood samples of $2-5 \mathrm{ml}$ were obtained from 25 normal infants under 4 months of age, 27 normal adults and eight infants suspected of epimerase deficiency on the basis of elevated levels of Gal-1-P and normal GALT activity found by newborn screening. Whenever possible, blood samples were also obtained from the parents of the probands. The blood was collected in sodium heparinized tubes. The plasma and the buffy coat were removed after centrifugation and the erythrocytes were 
washed three times with equal volumes of $0.9 \mathrm{~g} \% \mathrm{NaCl}$. Following the final centrifugation, the saline was completely removed and the packed cells were immediately frozen. Epimerase was found to be stable in the frozen state for at least 3 days. On the other hand, epimerase is not stable at room temperature. All blood samples were sent frozen to the Biochemical Genetics Laboratory at Childrens Hospital Los Angeles.

Prior to the enzyme assay, the red cells were thawed and $0.5 \mathrm{ml}$ of the hemolysate $(100 \%)$ was added to $0.5 \mathrm{ml}$ of $0.02 \mathrm{M}$ nicotinamide. Nicotinamide serves to inhibit NADase which otherwise reduces the epimerase activity [18]. To ensure complete hemolysis, the mixture was frozen and thawed three times in an alcohol-dry ice bath.

The principle of the epimerase assay is based on the following enzyme coupled reactions which are carried out separately:

$\mathrm{UDPGal} \underset{\text { (Epimerase) }}{\stackrel{\mathrm{NAD}^{+}}{\mathrm{N}}} \mathrm{UDPGlc}$

$\mathrm{UDPGlc}+2 \mathrm{NAD}^{+} \underset{\text { (UDPGlc dehydrogenase) }}{\longrightarrow} \mathrm{UDPGA}+2 \mathrm{NADH}+2 \mathrm{H}^{+}$

UDPGA designates uridine diphosphate glucuronic acid.

The amount of NADH generated in the second reaction is measured fluorometrically and is proportional to the epimerase activity in the first reaction.

All assays were carried out in duplicate. For the first reaction, $0.1 \mathrm{ml}$ of the $50 \%$ hemolysate in $0.02 \mathrm{M}$ nicotinamide was incubated with $0.05 \mathrm{ml}$ of $5 \mathrm{mM}$ UDPGal, $0.1 \mathrm{ml}$ of $1 \mathrm{M}$ glycine buffer ( $\mathrm{pH} 8.7$ ) and $0.05 \mathrm{ml}$ of $0.01 \mathrm{M}$ NAD. For the blank, water was substituted for UDPGal. Samples were incubated at $37^{\circ} \mathrm{C}$ for $20 \mathrm{~min}$, heated at $100^{\circ} \mathrm{C}$ for $3 \mathrm{~min}$, cooled in an ice bath and finally centrifuged at room temperature, $1000 \times g$ for 5 min to obtain a clear supernatant.

The second reaction contained $1.0 \mathrm{ml}$ of $0.1 \mathrm{M}$ glycine buffer $(\mathrm{pH} 8.7), 0.1 \mathrm{ml}$ of $0.01 \mathrm{M} \mathrm{NAD}, 0.03 \mathrm{ml}$ of supernate from the first reaction and $25 \mu 1$ of UDPGlc dehydrogenase (corresponding to $0.005 \mathrm{U}$ ). Samples were incubated at room temperature for a period of $60-80 \mathrm{~min}$ and maximum fluorescent readings were recorded in a Turner fluorometer model 112 with primary filter No. 7-60 and secondary filter No. 48 and a setting of $1 \times$. A standard curve was generated by running the second reaction using dilutions of a $0.5 \mathrm{mM}$ UDPGlc solution. Under our experimental conditions, $10 \mathrm{nmol}$ of UDPGlc gave a fluorescent reading of 72 units. Epimerase activity is expressed as $\mu$ mols UDPGlc formed $/ \mathrm{h} / \mathrm{g} \mathrm{Hb}$.

\section{Results}

Erythrocyte UDPGal-4-epimerase activities in normal individuals are shown in Table 1 . As a group, the activity is higher in the infants under 4 months of age than in adults $(P<0.001$, Student's $t$ test $)$.

All of the eight infants with erythrocyte epimerase deficiency detected by newborn 
TABLE 1

Erythrocyte UDPGal-4-epimerase activities in normal controls

\begin{tabular}{lllll}
\hline Normal controls & No. & Mean & SD & Range \\
\hline Infants (2 wks to 4 mos) & 25 & 23.9 & 4.7 & $14.8-30.9$ \\
Adults & 27 & 18.4 & 3.1 & $14.3-26.3$ \\
\hline
\end{tabular}

Epimerase activity expressed as $\mu \mathrm{mols} / \mathrm{h} / \mathrm{g} \mathrm{Hb}$.

screening for galactosemia showed elevated 'total galactose' (galactose and/or galactose-1-phosphate) values of over $20 \mathrm{mg} / \mathrm{dl}$ and normal GALT activity by the spot enzyme assay (Table 2). The deficiency in epimerase activity ranged from 0 to 3.8 units (normal mean activity is $23.9 \pm 4.7$ units). Six of the eight infants with epimerase deficiency are black while the remaining two are caucasian. The deficiency was found in both males and females. All but one were known or reported to be clinically normal during the neonatal period. The exception is an infant (CR) who had neonatal jaundice which subsequently resolved. Patient LE has a congenital cardiac lesion (venticular septal defect) and was discovered to have thrombocytopenia at age 2 years. She is now under study for a possible blood dyscrasia. It is unclear whether this is related to the epimerase deficiency.

Figure 1 shows the pedigree analyses of the five families in which the parents were also studied. The results are consistent with autosomal recessive inheritance with the obligate carriers having about $1 / 2$ normal values. For the black family, HA, two children and their father were found to have very low epimerase activity. We cannot clearly interpret the result in the father for family WA. It appears that there is a spectrum of enzyme deficiency among the blacks which suggests the possibility of variant forms.

TABLE 2

Erythrocyte UDPGal-4-epimerase deficiency

\begin{tabular}{lllllll}
\hline Case No. & Fam. & Sex & Race & Epim. act. & Gal+Gal-1-P & Screen method \\
\hline 1 & LE & F & W & 0 & 50 & microbiological \\
2 & HA & M & B & 0.3 & $20-40$ & microbiological \\
3 & CR & F & B & 1.4 & $20-40$ & microbiological \\
4 & NO & M & B & 2.7 & 36.8 & Gal deh/Alk phos \\
5 & SO & M & W & 3.8 & 31.0 & Gal deh/Alk phos \\
6 & LE & F & B & 2.7 & 24.3 & Gal deh/Alk phos \\
7 & WA & F & B & 2.3 & 54.4 & Gal deh/Alk phos \\
8 & PA & F & B & 3.4 & 22.8 & Gal deh/Alk phos \\
\hline
\end{tabular}

Epimerase activity expressed as $\mu \mathrm{mols} / \mathrm{h} / \mathrm{g} \mathrm{Hb}$.

$\mathrm{Gal}+\mathrm{Gal}-1-\mathrm{P}$ concentration expressed as $\mathrm{mg} / \mathrm{dl}$. 

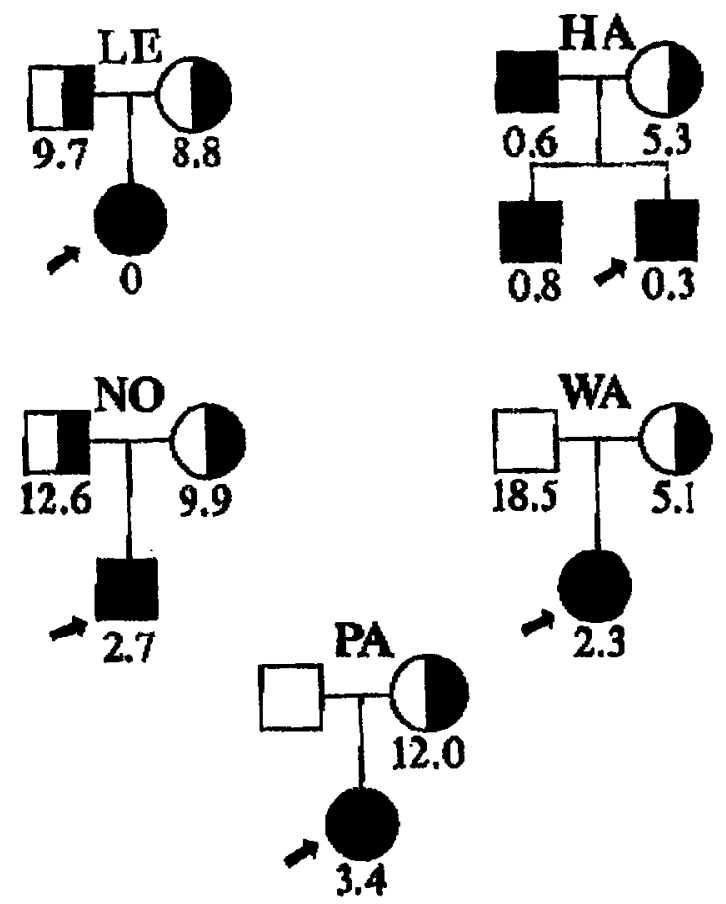

Fig. 1. Pedigree analysis of erythrocyte UDPGal-4-epimerase deficiency.

\section{Discussion}

The first case of epimerase deficiency in man was reported by Gitzelmann in Switzerland in a newborn screening program for galactosemia [19]. Microbiological assay revealed increased levels of total galactose (galactose and/or Gal-1-P) in the newborn blood sample. Subsequent follow-up study when the patient was on a regular diet of cow's milk showed erythrocyte Gal-1-P levels between 14 and $18.5 \mathrm{mg} / \mathrm{dl}$. The infant was healthy. Following this original publication, Gitzelmann identified several more patients, including three newborns, one older sibling and three women over 60 years of age in family studies [12]. All were healthy despite the absence of epimerase activity in both red and white blood cells. However, epimerase activity in cultured skin fibroblasts and liver was near normal.

Fujimura et al. developed a new mass screening for epimerase deficiency in Japan [20] and the first case from Japan was reported in 1980 [16]. The levels of erythrocyte Gal-1-P in this case varied from 15 to $42 \mathrm{mg} / \mathrm{dl}$ in RBC. Subsequently another case of epimerase deficiency was reported from Japan [21]. However, erythrocyte epimerase activity in this child was $7.5 \%$ of the normal level, which is not as deficient as the cases reported by Gitzelmann et al. [12]. Analysis of galactose metabolites in blood by thin layer chromatography showed the accumulation of either Gal-1-P or UDPGal or both. It is of interest that the UDPGal levels in the erythrocytes of our two patients (patient LE and another patient not included in Table 2) determined 
by our enzymatic assay were 2-3-times that of the normal controls. Another case of erythrocyte epimerase deficiency reported by Bowling et al. in Australia [22] had increased erythrocyte Gal-1-P $(10,000 \mathrm{nmol} / \mathrm{g} \mathrm{Hb}$ vs. normal level of $<170 \mathrm{nmol} / \mathrm{g}$ $\mathrm{Hb})$ and only slightly increased plasma galactose $(70 \mathrm{nmol} / \mathrm{l}$ vs. normal level of $<40 \mathrm{nmol} / \mathrm{l}$ ). Thus, in epimerase deficiency Gal-1-P is much more increased than galactose, which may show only a slight elevation. Gitzelmann modified the original Paigen test by the addition of alkaline phosphatase to release galactose from Gal1-P so that epimerase deficiency can be detected [23].

Even though galactosemia screening in the US has been performed for over 2 decades, only three cases of erythrocyte epimerase deficiency have been reported [17]. In the present study we include two of these three patients and additional patients identified in other screening programs. Accumulation of Gal-1-P to the level of $20 \mathrm{mg} \%$ or higher seemed to be the most consistent finding when the infants were on normal lactose-containing formula or breast feedings. Since all cases had normal transferase activity, these cases would have been missed if the primary screening test for galactosemia was based on GALT activity alone, such as the spot enzyme assay of Beutler and Baluda [8]. Since many programs in the US use this screening approach, it is likely that epimerase deficiency is far more frequent than would be suggested by the few cases we are reporting.

So far seven of these eight children with erythrocyte epimerase deficiency are clinically normal in follow-up studies, unlike the two cases of epimerase deficiency which presented with clinical problems somewhat similar to those of classical galactosemia $[14,15]$. It is of interest that both of these latter patients are of Pakistani ethnic background. It is possible that the blood dyscrasia in one of our cases is related to the epimerase deficiency as she is the only child among the eight we are reporting who had no detectable epimerase activity. This is currently under investigation. If there is a relationship, this would rcpresent a ncw finding in cpimerase deficiency. This patient has none of the clinical features described for the Pakistani patients. Epimerase assay in cultured skin fibroblasts would be helpful to establish the extent of the enzyme deficiency. At this time we are not aware of any cases of epimerase deficiency with severe clinical manifestations detected through newborn screening programs for galactosemia. In addition to the findings of accumulated Gal-1-P, UDPGal levels in the erythrocytes of the two Pakistani patients were also elevated.

In agreement with Gitzelmann and others [12,16,21], it seems that erythrocyte epimerase deficiency is an inherited autosomal recessive trait. The spectrum of enzyme deficiency in red cells and in other tissues suggests, however, that there are at least several mutations in the gene that produce this deficiency for epimerase. Mitchell et al. suggested that the enzyme deficiency in the benign form might be due to the presence of an unstable variant [13]. So far the gene for epimerase in man has not been molecularly characterized, although it has been localized to the short arm of chromosome 1 [24].

The present study confirms the likelihood that erythrocyte epimerase deficiency has a relatively high frequency in the black population. Based on the Maryland study [17], the frequency of epimerase deficiency in blacks has been estimated at 
approx. $1 / 8,000$ to $1 / 12,000$. In Mississippi with a population equally divided between blacks and caucasians, only blacks so far have been found to have epimerase deficiency. Following the completion of this study, nine more cases of erythrocyte epimerase deficiency have been identified. These include four from Maryland, three of which are in blacks, and one in a Pakistani/caucasian infant; four from Mississippi, all of whom are black, and the remaining one from Michigan who is also black.

It is of interest that the prevalence of mutants of all three enzymes of the galactose metabolic pathway (galactokinase, GALT and epimerase) differ between blacks and caucasians. A galactokinase in blacks with lower activity than normal has been described [25] and the 'Negro variant' of GALT deficiency (galactosemia) with residual liver activity is well known [26]. Now epimerase deficiency can be included in this group. With respect to the epimerase activity which is affected by NADase in the in vitro assay, NADase deficiency in blacks has also been reported [27]. The significance of these mutants in the American black population is not yet known.

\section{Acknowledgements}

We would like to acknowledge the support of newborn screening programs by the Department of Health and Mental Hygiene, MD; Department of Public Health, MI; Department of Health, MS, and Department of Public Health, the Commonwealth of Massasschutte. The work is also supported in part by the Childrens Hospital Los Angeles Research Program.

\section{References}

1 Segal S. Disorders of galactose metabolism. In: Scriver CR, Beaudet AL, Sly WS, Valle D, eds. The metabolic basis of disease. New York: McGraw-Hill Book, 1989;452.

2 Guthrie R. Routine screening for inborn errors in the newborn: 'in-hibition assays,' instant bacteria and raultiple tests. In: Proc Intern Copenhagen Cong Scient Study of Mental Retard, Copenhagen, $1964 ; 2: 495$.

3 Paigen K, Pacholec F, Levy HL. A new method of screening for inherited disorders of galactose metabolism. J Lab Clin Med 1982;99:895.

4 Fujimura Y, Ishii S, Kawamura M, Naruse H. Microdetermination of galactose and galactose-1phosphate in dried blood spots. Anal Biochem 1981;117:187.

5 Misuni H, Wada H, Kawakami M, Ninomiya H. Sueishi T, Ichiba Y, Shohmori T. Detection of UDP-galactose-4-epimerase deficiency in a galactosemia screening program. Clin Chim Acta $1981 ; 116: 101$.

6 Hill GN, O'Reilly D, Robertson E. A simple screening test for galactosemia based on accumulation of galactose and galactose-1-phosphate. In: Naruse H, ed. Neonatal screening. Amsterdam: Excerpta Media, 1983;252.

7 Hoffman GL, Laessig RH, Hassemer DJ, Makowski ER. Dual-channel continuous-flow system for determination of phenylalanine and galactose: application to newborn screening. Clin Chem 1984;30:287.

8 Beutler E, Baluda MC. A simple spot screening test for galactosemia. J Lab Clin Med 1966;68:137.

9 Hochella NJ, Hill JB. Fluorometric screening procedure for galactosemia utilizing the autoanalyzer. Clin Chem 1969;15:949. 
10 Levy HL, Hammersen G. Newborn screening for galactosemia and other galactose metabolic defects. J Pediatr 1978;92:871.

11 Gitzelmann R, Steinmann B. Uridine diphosphate galactose 4-epimerase deficiency. II. Clinical followup, biochemical studies and family investigation. Helv Paediat Acta 1973;28:497.

12 Gitzelmann R, Steinmann B, Mitchell B, Haigis E. Uridine di-phosphate galactose 4-epimerase deficiency. IV. Report of eight cases in three families. Helv Paediat Acta 1976;31:441.

13 Mitchell B, Haigis E, Steinmann B, Gitzelmann R. Reversal of UDPgalactose 4-epimerase deficiency of human leukocytes in culture. Proc Natl Acad Sci USA 1975;72:5026.

14 Holton JB, Gillett MG, MacFaul R, Young R. Galactosemia: a new severe variant due to uridine diphosphate galactose-4-epimerase deficiency. Arch Dis Child 1981;56:885.

15 Sardharwalla IB, Wraith JE, Bridge C, Fowler B, Roberts SA. A patient with severe type of epimerase deficiency galactosemia. J Inherit Metab Dis 1988;11: S 2,249.

16 Ichiba $\mathrm{Y}$, Namba N, Misumi H. Uridine diphosphate galactose-4-epimerase deficiency. Am J Dis Child 1980;134:995.

17 Cowan T, Raffel L, Ng W, Xu Y, Panny S, Blitzer M. Frequency of UDPgal-4-epimerase (EP) deficiency identified by newborn screening. Am J Hum Genet Abst 1991;S 49:328.

18 Bergren WR, Ng WG, Donnell GN. Uridine diphosphate galactose 4-epimerase in human and other mammalian hemolysates. Biochim Biophys Acta 1973;315:464.

19 Gitzelmann R. Deficiency of uridine diphosphate galactose-4-epimerase in blood cells of an apparently healthy infant - preliminary communication. Helv Paediat Acta 1972;27:125.

20 Fujimura Y, Kamura M, Naruse H. A new mass screening method of detecting UDP-galactose-4epimerase deficiency. Tohuku J Exp Med 1980;131:15.

21 Oyanagi K, Nakata F, Hirano S, Sogawa H, Takayanagi N, Minami R, Tsugawa S, Nakao T, Ichihara N. Uridine diphosphate galactose 4-epimerase deficiency. Eur J Pediatr 1981;135:303.

22 Bowling FG, Fraser DKB, Clague AE, Hayes A, Morris DJ. A case of uridine diphosphate galactose4-epimerase deficiency detected by neonatal screening for galactosemia. Med J Aust 1986; 144:150.

23 Gitzelmann R. Newborn screening for inherited disorders of galactose metabolism. In: Bickel H, Guthrie R, Hammersen G, eds. Neonatal screening for inborn errors of metabolism. Berlin: Springer, 1980;67.

24 Lin MS, Oizumi J, Ng WG, Alfi OS, Donnell GN. Regional mapping of the gene for human UDPGal4-epimerase on chromosome 1 in mouse-human hybrids. Cytogenet Cell Genet 1979;24:217.

25 Tedesco TA, Bonow R, Miller K, Mellman WJ. Galactokinase: evidence for a new racial polymorphism. Science 1972;178:176.

26 Segal S. The Negro variant of congenital galactosemia. In: Hsia YY, ed. Galactosemia. Springfield, IL: Charles C Thomas, 1969;176.

$27 \mathrm{Ng}$ WG, Donnell GN, Bergren WR. Deficiency of erythrocyte nicotinamide adenine dinucleotide nucleosidase (NADase) activity in the Negro. Nature 1968;217:64. 